\title{
Wind Energy Dynamics of the Separately Excited Induction Generator
}

\author{
Oti S. Ejiofor ${ }^{1}$, Eya U. Candidus ${ }^{1}$, Madueme C. Victory ${ }^{1} \&$ Eze C. Ugochukwu ${ }^{1}$ \\ ${ }^{1}$ Department of Electrical Engineering, University of Nigeria, Nigeria \\ Correspondence: Oti Stephen Ejiofor, Department of Electrical Engineering, University of Nigeria, Nsukka, Enugu \\ State, Nigeria (400241). Tel: 234-8-039-472-998.
}

Received: November 9, 2018; Accepted: December 5, 2018; Published: January 29, 2019

The research is financed by the authors.

\begin{abstract}
This paper covers the analysis, dynamic modelling and control of an isolated self-excited induction generator (SEIG) driven by a wind turbine. The proposed dynamic model consists of induction generator, self-excitation capacitance and load model which are expressed in stationary d-q reference frame. The dynamic performance of SEIG is investigated under no load and on load. To predict the performance of the system, a MATLAB based simulation study using matlab embedded function block was carried out. Simulations from the variations of the speed and load display the dynamic behavior of the generator. A constant capacitor value of 100 micro-farads was used in this work. The simulation results obtained illustrate the changes in the voltage, currents, torque and magnetizing inductance of the generator. The wind velocity increase led to the increase in mechanical input from the wind turbine. This results in the increased rotor speed leading also to increased stator phase voltage. The obtained simulations also show that the output voltage of the induction generator depends greatly on its shaft speed and load; this poses a potential threat as it is capable of causing a significant variation in the power consumption in the load of the machine.
\end{abstract}

Keywords: drive train, excitation capacitor, gearbox, rotor, performance, wind turbine

\section{Introduction}

Apart from the common use as motors, three-phase induction machines are also used extensively as generators in electric power systems. Induction generators offer advantages for hydro and wind applications in terms of cost and simplicity. They also play an important role in the renewable energy industry today. Among the renewable energy sources wind energy has proven to be one of the most economical one (Ma, 2012). However, the need for an external power source to provide its excitation is a big limitation of induction generators. The possibility of using a Self-Excited Induction Generator (SEIG) where a three-phase capacitor bank is connected across the stator terminals to supply the reactive power requirement of a load and generator was discovered by Basset and Potter in the 1930s (Basset \& Potter, 2009). An external mechanical power source drives the induction machine giving rise to residual magnetism which produces emf in the stator that is applied to the capacitor bank which causes current flow in the stator and creating a magnetizing flux in the machine (Ma, 2012). An induction machine connected and excited in this manner is capable of acting as a standalone generator supplying power (real and reactive) to a load. In this mode of operation, the capacitor bank supplies the reactive power requirement of the load and generator while the real power demand of the terminal load is supplied by the prime mover. These machines are very economical, reliable and are available in the ranges of fractional horse power (FHP) to multi -megawatt capacity (Ofualagba \& Ubeku, 2011). Also, unlike synchronous machines, induction machines can operate at variable speeds. There is need for gearbox since there should exist a downward to upward conversion at the side of wind turbine in favour of the speed or rotor, which is consequent of the induction machine type; that is whether it squirrel caged or wound rotor type. Ruggedness, simplicity and cheap characterized the choice of squire cage rotors' use in stand-alone schemes as against wound rotor type which is capable of high starting torque yield with the attendant rotor power extraction at the expense of power electronics cost at the rotor (Ofualagba \& Ubeku, 2011). An induction motor can operate as a generator in super synchronous speed raised by an overhauling type of load, or by lowering the inverter frequency below the machine speed, when there is a converter-fed machine drive (Tamas \& Szekely, 2013). An induction generator with a squirrel cage rotor can be specifically designed to work with wind turbines, with a larger slip factor, convenient deformation in the torque curve, winding sized to support higher saturation current and increased number of poles. In application to wind energy conversion systems, 
the induction generator produces electricity through various energy conversions. The kinetic energy from the wind is converted into mechanical energy which is then converted into electricity that is sent to a power grid. The turbine components responsible for these energy conversions are the rotor and the generator (ni.com, 2017). Varying speed operation will result to varying rotor speed which will affect the behavior of the generator. For an induction generator, there is a load current limit which if exceeded, the residual magnetism falls to zero and the machine is de-excited. When this happens, there are four methods available for its re magnetization (Simoes \& Farret, 2015): (i) maintain a spare capacitor always charged and, when necessary, discharge it across one of the generator's phases, (ii) use a charged battery, (iii) use a rectifier fed by the distribution network, or (iv) keep the induction generator running for about ten minutes so the reduced presence of the residual magnetism in the iron can be fully recovered. This study is to be demonstrated using the model of a SEIG for wind power generation. Matlab program is used in modelling the equations, the analysis and simulation will be so useful since hither to, the dynamic response behavior of the system can be predicted.

\subsection{The Wind Energy System}

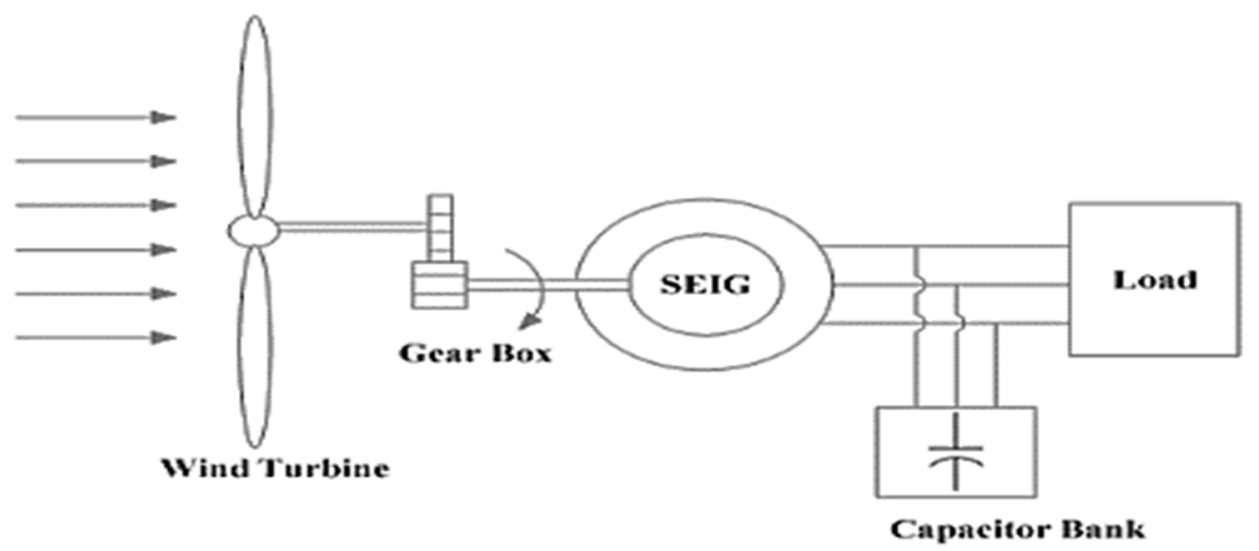

Figure 1. Wind energy conversion system

The wind power generation system is shown in Figure 1. The wind turbine consists of gearbox, generator, hub, rotor, low-speed shaft, high-speed shaft. The wind turbine is coupled to the shaft of an induction generator (SEIG) through a gear box. The IG is connected to capacitor banks for self-excitation. Wind energy turbines could be classified as horizontal-axis or vertical-axis (Martinez, 2007) that is, in terms of the axis around which the turbine blades rotate. Most are horizontal axis wind turbines (HAWT), but there are some with blades that spin around a vertical axis (VAWT). The only vertical-axis turbine which has been manufactured commercially at any volume is the Darrieus machine, named after the French Engineer Georges Darrieus who patented the design in 1931 (Masters, 2004). The shape of the blades is that which would result from holding a rope at both ends and spinning it around a vertical axis, giving it a look that is like a giant "egg whisk".

Another wind turbine classification is whether the rotor is allowed to run at variable speed or constrained to operate at constant speed. Fixed-speed wind turbines (popularly known as the "Danish concept") (Singh, 2014) are the most basic utility-scale wind turbines in operation. They operate with very little variation in turbine rotor speed and employ squirrel-cage induction machines directly connected to the grid. Because of the limited speed range in which these turbines operate, they are prone to torque spikes that may damage the mechanical subsystems within a turbine and cause transients in the electrical circuitry. Variable-speed wind turbines are designed to operate at a wide range of rotor speeds. According to (AI-Nuaim, 2005) wind turbine and induction generator models are respectively classified as shown below.

a) Constant speed, constant frequency systems are grouped as Variable Pitch Ratio gear, Variable pitch twostage (or multi-stage) ratio gear and Fixed Pitch Variable Ratio gear.

b) Variable speed, constant frequency with series connected circuit. For the induction generator model;(i) Nonisolated-where excitation required are provided by an external A.C source and (ii) Isolated type (self-excited), in which excitation is provided by a terminal capacitor.

\section{Methodology}

2.1 Modelling of the Turbine and Drive Train

The kinetic energy in air of the blade of mass $m$ moving with a certain speed $V w$ is given by 


$$
\mathrm{E}=\frac{1}{2} \cdot \mathrm{m} \cdot V w^{2}
$$

The tip speed ratio, $\lambda$ is the ratio between the speed of the tips of the blades of a wind turbine and the speed of the wind and is defined as

$$
\lambda=\frac{\omega_{w} R}{V_{w}}
$$

where $\omega_{\mathrm{m}}$ is the blades angular velocity $(\mathrm{rad} / \mathrm{s}), R$ is the wind blade radius $(\mathrm{m})$ and $v$ is the wind speed $(\mathrm{m} / \mathrm{s})$.

Based on the Betz theory, the mechanical power $P m$ extracted from wind energy can be written as

$$
P m=0.5 C_{p}(\lambda, \beta) \rho V_{w}^{3} R^{2}
$$

Where $C_{p}(\lambda, \beta)$ is the wind speed power coefficient, $\rho$ is the air density $\left(\mathrm{kg} / \mathrm{m}^{3}\right)$ and $V_{w}$ is the wind speed $(\mathrm{m} / \mathrm{s})$.

The aerodynamic efficiency of a wind turbine is described by the power coefficient $C_{p}(\lambda, \beta)$ which is dimensionless and nonlinear.

The mechanical torque is given as

$$
T=C_{p .} \omega_{w}^{2}
$$

The equation of motion of the induction generator is given by

$$
H g \frac{d \omega g}{d t}=T e+\frac{T m}{n}
$$

The mechanical torque $m T$ can be modelled with the following equation

$$
\begin{gathered}
T m=\mathrm{K} \cdot \frac{\theta}{n}+D \frac{\omega_{g}-\omega_{w}}{n} \\
\frac{d \theta}{d t}=\omega_{g}-\omega_{w}
\end{gathered}
$$

where $n$ is the gear ratio, $\theta$ is the angle between the turbine rotor and the generator rotor, $\omega_{w}, \omega_{g}, H g$ are the turbine and generator rotor speed and inertia constant, respectively, $\mathrm{K}$ and $\mathrm{D}$, are the drive train stiffness and damping constants, $T w$ is the torque provided by the wind and $T e$ is the electromagnetic torque.

\subsection{Modelling and Analysis of Self-Excited Induction Generator}

For the modelling of SEIG, the iron and the rotational losses are neglected, while the magnetizing inductance is used instead of the magnetizing reactance since it varies with the frequency. The Self-Excited Induction Generator model in the D-Q stationary reference frame (Simoes \& Farret, 2015) is shown in the figure 2 below.

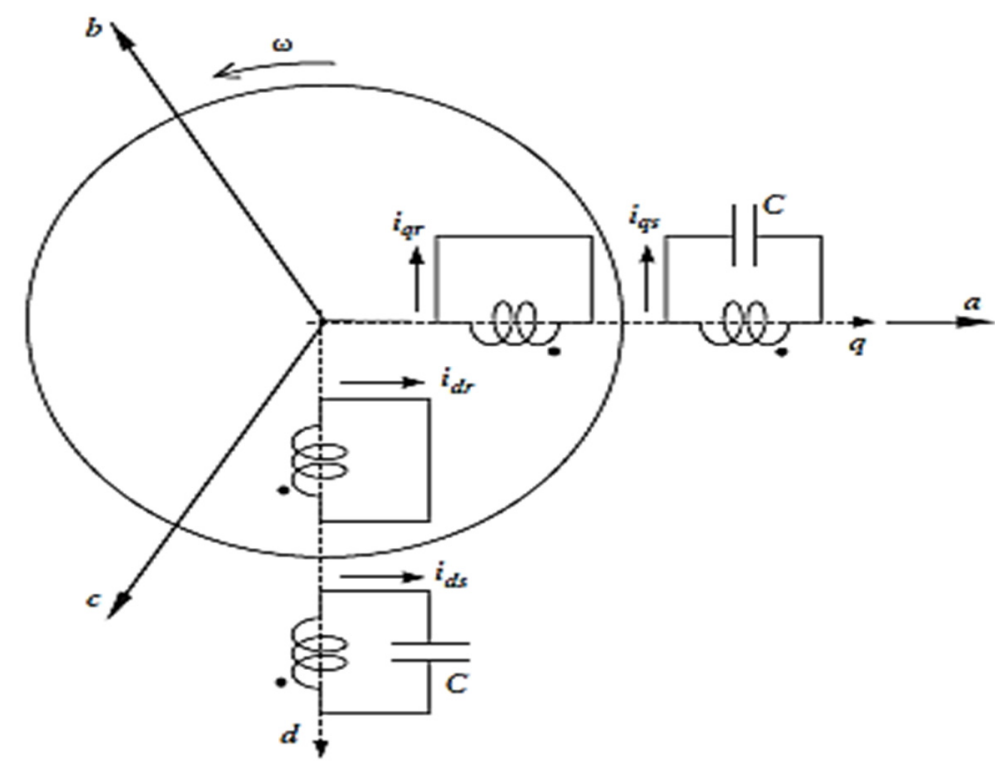

Figure 2. Representation of SEIG in $d-q$ axis 


\subsubsection{Unloaded SEIG Model}

The D-Q models of SEIG in the stationary reference frame (Umoh, 2010) is shown in figures 3 and 4.

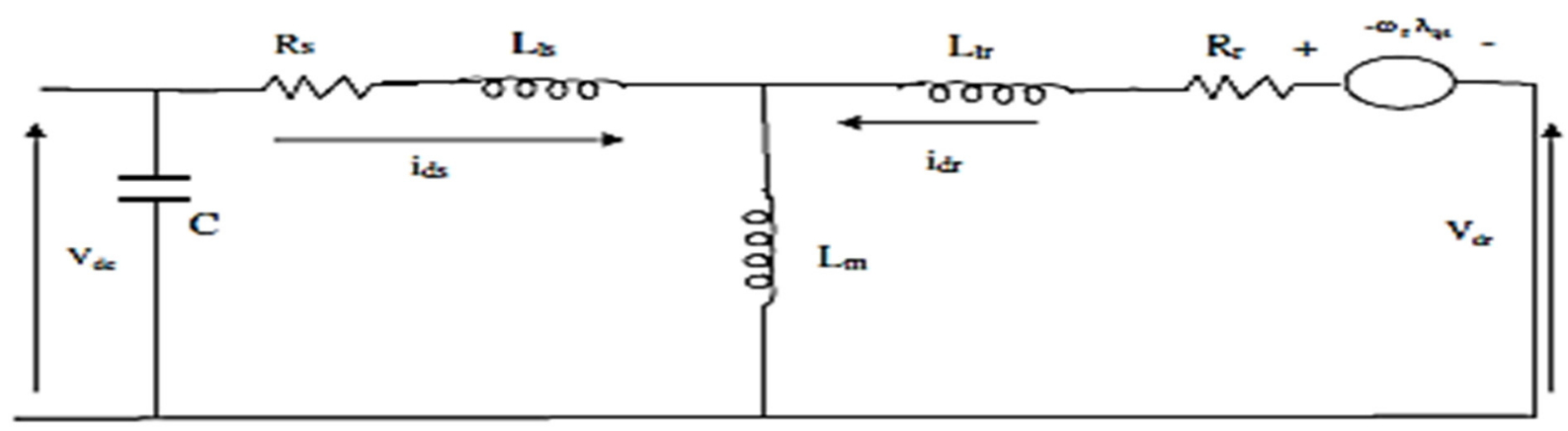

Figure 3. D-Q model of SEIG in Stationary reference frame (d-axis)

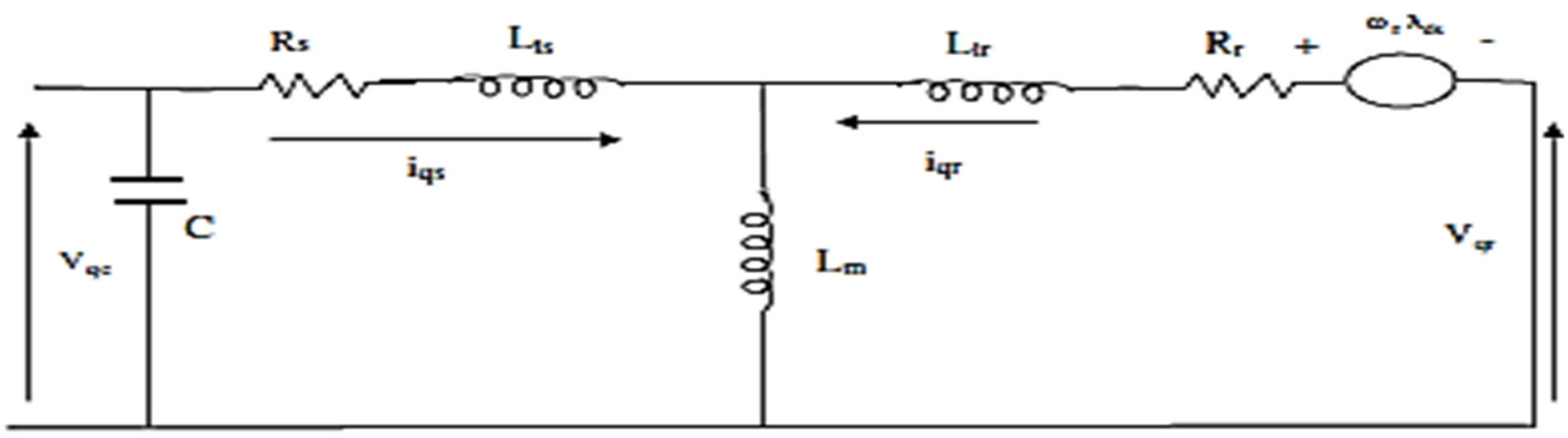

Figure 4. D-Q model of SEIG in Stationary reference frame (q-axis)

A self-excited induction generator (SEIG) with a capacitor is initially considered to be operating at no load. The reference position is put on the stator under every normal operating condition including transient ones. The subscript $s$ refers to the stator, while $r$ refers to the rotor. The voltage drops across the capacitor (direct axis, $v c d$ and quadrature axis, $v c q$ ) is included in the matrix.

The capacitor voltages are represented

$$
\begin{gathered}
V_{c q}=\frac{1}{c} \int i_{q s} d t+V_{c q 0} \\
V_{c d}=\frac{1}{c} \int i_{d s} d t+V_{c d 0}
\end{gathered}
$$

Where $V_{c q 0}=V_{c q}$, at $\mathrm{t}=0$ and $V_{c d 0}=V_{c d}$, at $\mathrm{t}=0$ are the initial voltage along the $\mathrm{q}$-axis and $\mathrm{d}$-axis capacitors, respectively (Sen, 1996). The rotor flux linkage is given by

$$
\begin{gathered}
\lambda_{q r}=L_{m} i_{q s}+L_{r} i_{q r}+\lambda_{q r 0} \\
\lambda_{d r}=L_{m} i_{d s}+L_{r} i_{d r}+\lambda_{d r 0}
\end{gathered}
$$

Where $L_{s}=L_{l s}+L_{m}$ and $L_{r}=L_{l r}+L_{m} ; \lambda_{q r 0}=\lambda_{q r}$ at $\mathrm{t}=0$, and $\lambda_{d r 0}=\lambda_{d r}$ at $\mathrm{t}=0$ are the remnant or residual rotor flux linkages along the q-axis and d-axis, respectively.

Let $\omega_{r}$ be the electrical angular speed of rotor, $K_{q r 0}=\omega_{r} \lambda_{q r 0}$ and $K_{d r 0}=\omega_{r} \lambda_{d r 0}$ represent the initial daxis and q-axis induced voltages respectively. The constant $K_{d r 0}$ and $K_{q r 0}$ are due to the remnant or residual magnetic flux in the core. $\omega_{r}$ is the equivalent electrical rotor speed in radians/second. That is, Electrical speed = number of pole pairs $\mathrm{x}$ mechanical speed (Induction generator, 2017).

The d-q model of a self-excited induction generator, in the stationary stator reference frame has its matrix equation given as: 


$$
\left[\begin{array}{cccc}
R_{s}+p L_{s}+1 / p C & 0 & p L_{m} & 0 \\
0 & R_{s}+p L_{s}+1 / p C & 0 & p L_{m} \\
p L_{m} & -\omega_{r} L_{m} & R_{r}+p L_{r} & -\omega_{r} L_{m} \\
\omega_{r} L_{m} & p L_{m} & \omega_{r} L_{m} & R_{r}+p L_{r}
\end{array}\right]\left[\begin{array}{c}
i_{q s} \\
i_{d s} \\
i_{q r} \\
i_{d r}
\end{array}\right]+\left[\begin{array}{c}
V_{c q o} \\
V_{c d 0} \\
-K_{q r 0} \\
K_{d r 0}
\end{array}\right]=\left[\begin{array}{l}
0 \\
0 \\
0 \\
0
\end{array}\right]
$$

Where $Z$ is the impedance matrix, $I_{v}$ is the stator and rotor currents vector and $V_{v}$ is the voltage vector due to initial condition (Oti, Nwosu \&Agu, 2013).

\subsubsection{Modelling of SEIG under Different Loading}

A load represented by ZL is connected across the excitation capacitor to represent the loaded condition of the SEIG. The nature of the load can be resistive and an inductive.

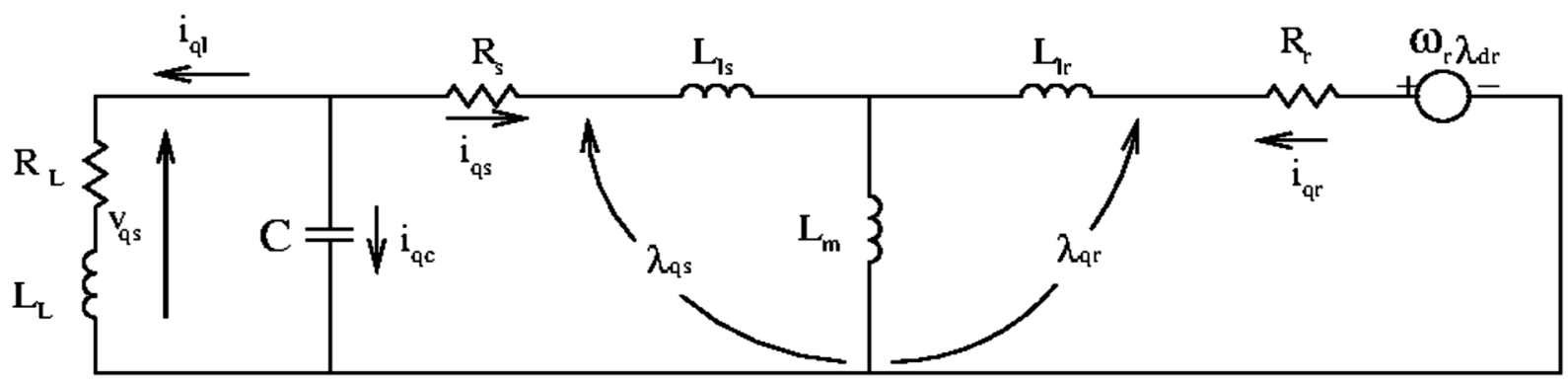

Figure 5. Circuit model of loaded SEIG in dq stationary reference frame (q-axis circuit)

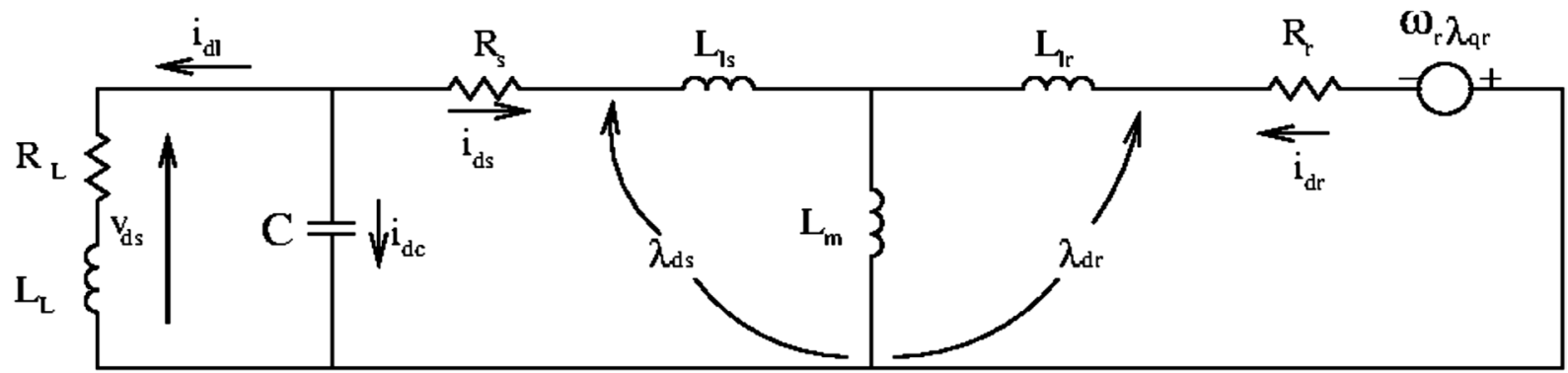

Figure 6. Circuit model of loaded SEIG in dq stationary reference frame (d-axis circuit)

From above circuit by applying KVL we can get the voltage equations as follows

$$
\begin{gathered}
V_{q s}=R_{s} i_{q s}+\frac{d \lambda_{q s}}{d t}+\omega \lambda_{d s} \\
V_{d s}=R_{s} i_{d s}+\frac{d \lambda_{d s}}{d t}-\omega \lambda_{q s} \\
V_{q r}=R_{r} i_{q r}+\frac{d \lambda_{q r}}{d t}+\left(\omega-\omega_{r}\right) \lambda_{d r} \\
V_{d r}=R_{r} i_{d r}+\frac{d \lambda_{d r}}{d t}-\left(\omega-\omega_{r}\right) \lambda_{q r}
\end{gathered}
$$

Where $V_{d r}=V_{q r}=0$ (short circuited rotor)

The following differential equations can be derived from the equations

$$
\begin{gathered}
\frac{d i_{q s}}{d t}=M\left[-L_{s} R_{s} i_{q s}-\omega_{r} L_{m}^{2} i_{d s}+L_{m} R_{r} i_{q r}-\omega_{r} L_{m} L_{r} i_{d r}+L_{r} V_{q s}\right] \\
\frac{d i_{d s}}{d t}=M\left[-L_{r} R_{s} i_{d s}-\omega_{r} L_{m}^{2} i_{q s}+L_{m} R_{r} i_{d r}-\omega_{r} L_{m} L_{r} i_{q r}+L_{r} V_{d s}\right]
\end{gathered}
$$




$$
\begin{gathered}
\frac{d i_{q r}}{d t}=M\left[L_{m} R_{s} i_{q s}+\omega_{r} L_{m} L_{s} i_{d s}-L_{s} R_{s} i_{q r}+\omega_{r} L_{s} L_{r} i_{d r}+L_{m} V_{q s}\right] \\
\frac{d i_{d r}}{d t}=M\left[L_{m} R_{s} i_{d s}-\omega_{r} L_{m} L_{s} i_{q s}-L_{s} R_{r} i_{d r}-\omega_{r} L_{s} L_{r} i_{q r}+L_{m} V_{d s}\right] \\
\text { Where } \mathrm{M}=\frac{1}{L_{m} L_{s}-L_{m}^{2}}
\end{gathered}
$$

The electromagnetic torque expression is given as

$$
T_{e}=\left(\frac{3}{2}\right)\left(\frac{P}{2}\right) L_{m}\left[i_{d s} i_{q r}-i_{q s} i_{d r}\right]
$$

Where $P$ is the number of poles, $L_{m}$ is the magnetizing inductance; $R_{S}$ and $R_{r}$ are the stator and rotor resistances respectively.

The expression for magnetizing current is given as

$$
i_{m}=\sqrt{\left(i_{d s}+i_{d r}\right)^{2}+\left(i_{q s}+i_{q r}\right)^{2}}
$$

\subsubsection{Modelling of Excitation Capacitor}

The capacitor model equations are as follows using d-q components of stator voltage as state variables.

$$
\begin{gathered}
i_{d c}=i_{d s}-i_{d L}, \quad i_{q c}=i_{q s}-i_{q L} \\
\frac{d V_{q s}}{d t}=\frac{i_{q s}-i_{q L}}{c}-\omega_{r} V_{d s}
\end{gathered}
$$

And

$$
\frac{d V_{d s}}{d t}=\frac{i_{d s}-i_{d L}}{C}-\omega_{r} V_{q s}
$$

Thus, the load equation is given in the following equations

$$
\frac{d i_{q L}}{d t}=\frac{V_{q s}-R_{L} i_{q L}-\omega_{r} L_{L} i_{d L}}{L_{L}}
$$

And

$$
\frac{d i_{d L}}{d t}=\frac{V_{d s}-R_{L} i_{d L}-\omega_{r} L_{L} i_{q L}}{L_{L}}
$$

\subsection{Magnetizing Inductance}

The magnetizing inductance follows a relationship pattern given in (Obe, Umoh \& Anih, 2011; Oti, Nwosu \&Agu, 2013) as shown below

$$
L_{m}=-1.56 \times 10^{11} V_{p h}^{4}+2.44 \times 10^{-8} V_{p h}^{3}-1.19 \times 10^{-5} V_{p h}^{2}+1.42 \times 10^{-3} V_{p h}+0.245
$$

Where, $\mathrm{Lm}$ the magnetizing inductance depends on the phase voltage Vph. This relationship between $\mathrm{Lm}$ and $\mathrm{Vph}$ takes into account the effect of the magnetizing inductance on self-excitation.

\section{Machine and Turbine Parameters}

The parameters of the machine and the wind turbine are as given in tables below.

Table 1. Parameters of Induction machine

\begin{tabular}{ll}
\hline \multicolumn{2}{l}{ Machine Parameters } \\
\hline Parameters & Values \\
\hline Rated Power & $3.6 \mathrm{~kW}$ \\
Rated Voltage & $415 \mathrm{~V}$ \\
Rated Current & $7.8 \mathrm{~A}$ \\
Rated Frequency & $50 \mathrm{~Hz}$ \\
\hline
\end{tabular}




\begin{tabular}{ll}
\hline Number of Poles & 4 \\
Stator Resistance & $1.66 \mathrm{Ohms}$ \\
Rotor Resistance & $2.74 \mathrm{Ohms}$ \\
Stator Inductance & $11.4 \mathrm{mH}$ \\
Rotor Inductance & $11.4 \mathrm{mH}$ \\
\hline
\end{tabular}

Table 2. Parameters of Wind turbine

\begin{tabular}{ll}
\hline \multicolumn{2}{l}{ Wind turbine Parameters } \\
\hline Parameters & Values \\
\hline Blade Radius & $35 \mathrm{~m}$ \\
Pitch angle & $0^{0}$ \\
Gear ratio & 65 \\
Rated wind speed & $13 \mathrm{~m} / \mathrm{s}$ \\
Tip speed ratio & 7.1 \\
\hline
\end{tabular}

\section{Results}

\subsection{Saturation Curve}

The magnetizing inductance is the main factor for voltage build up and stabilization of generated voltage for the unloaded and loaded conditions of the induction generator.

The SEIG model for simulated for 10 seconds on no load with excitation capacitance selected as $100 \mu \mathrm{f}$. The SEIG driven by constant speed prime mover with 1600rpm at no load and simulation result are shown in figures 7 and 8 below.

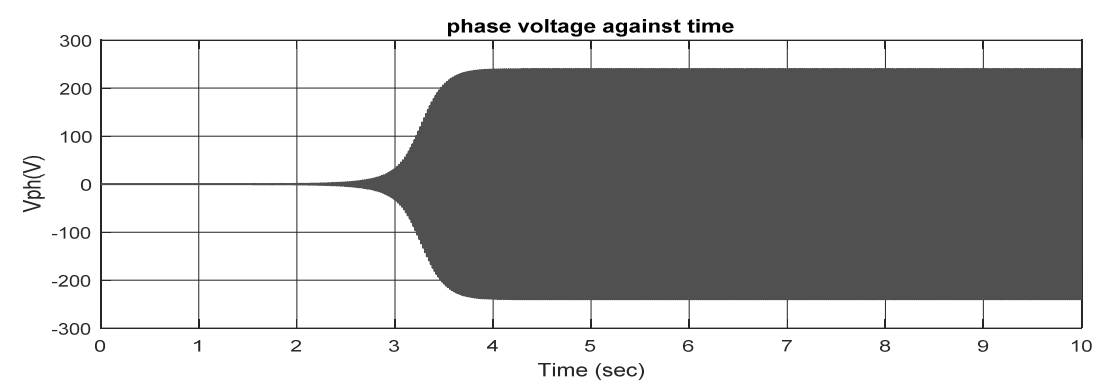

Figure 7. Voltage build up in a self-excited induction generator

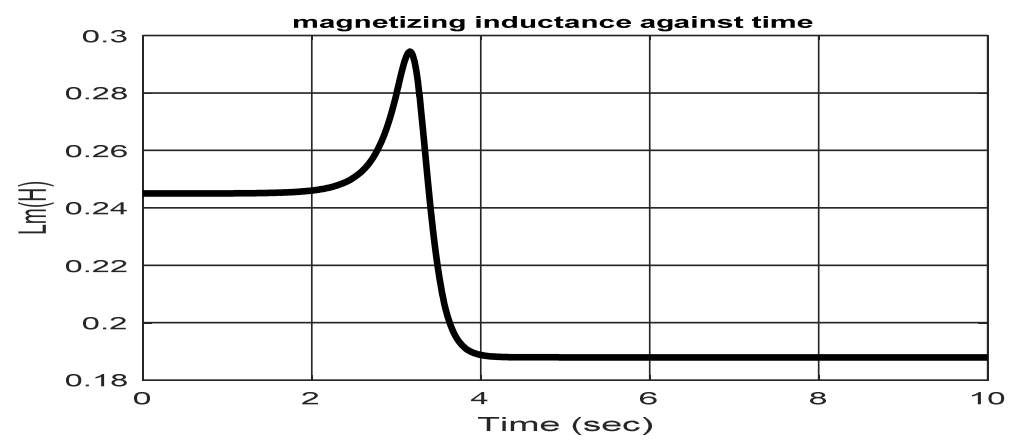

Figure 8. Variation of magnetizing inductance with voltage buildup.

The voltage and current waveforms of SEIG reach steady state within $3.8 \mathrm{sec}$. The steady state peak value of SEIG terminal voltage is 240 volts. Figure 7 shows the voltage buildup process, which demonstrates the variation of the terminal voltage within 10 seconds of the startup of the generator. From Figures 7 and 8 , the phase voltage slowly starts building up and reaches a steady-state value while the magnetization inductance starts from a value 0.245 . Magnetizing inductance increased rapidly to a value 0.294 at $t=3.13 \mathrm{sec}$. It also decreased to get a steady value 
of 0.188 at $\mathrm{t}=3.8$ seconds, therefore, the self-excitation traces the process of magnetic saturation of the core, and a stable output results with the machine core saturated.

\subsection{Loading Condition}

(i) Considering simulation results the WECS made up of the SEIG and the wind turbine being driven by at no-load and then loaded at 5 seconds

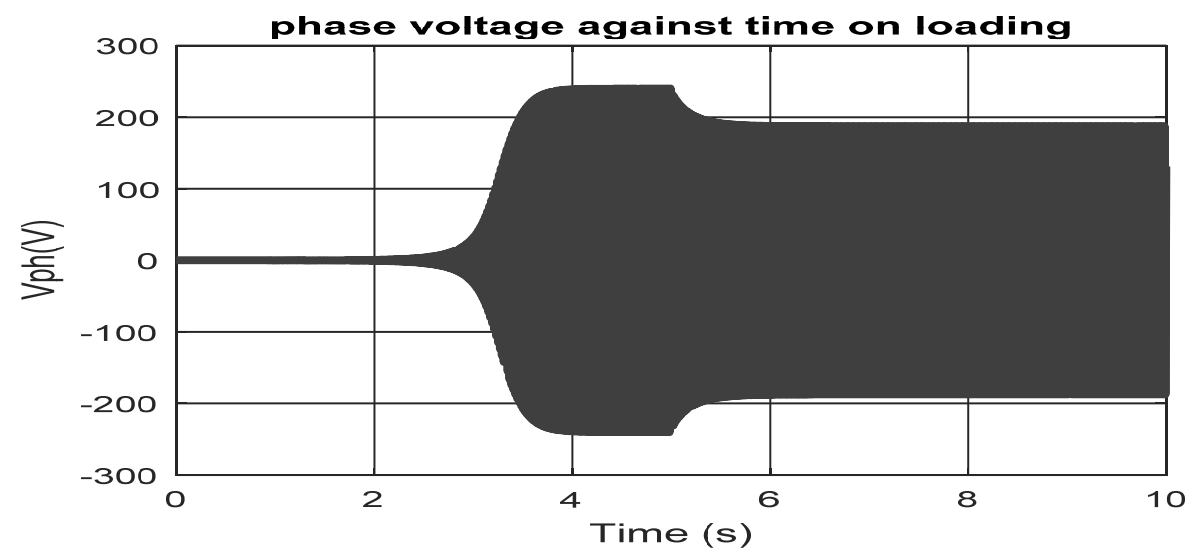

Figure 9. Phase voltage variations showing the effect of loading

The phase voltage decreased to a value $184 \mathrm{~V}$ and removing the load increased to a constant voltage of $240 \mathrm{~V}$. The generator's voltage drops when the load impedance is increased resulting in poor voltage regulation.

(ii) Loading with speed variations

The speed was increased to $1800 \mathrm{rpm}$ with a loading at $\mathrm{t}=5$ seconds. The simulation results are shown in figure 10 .

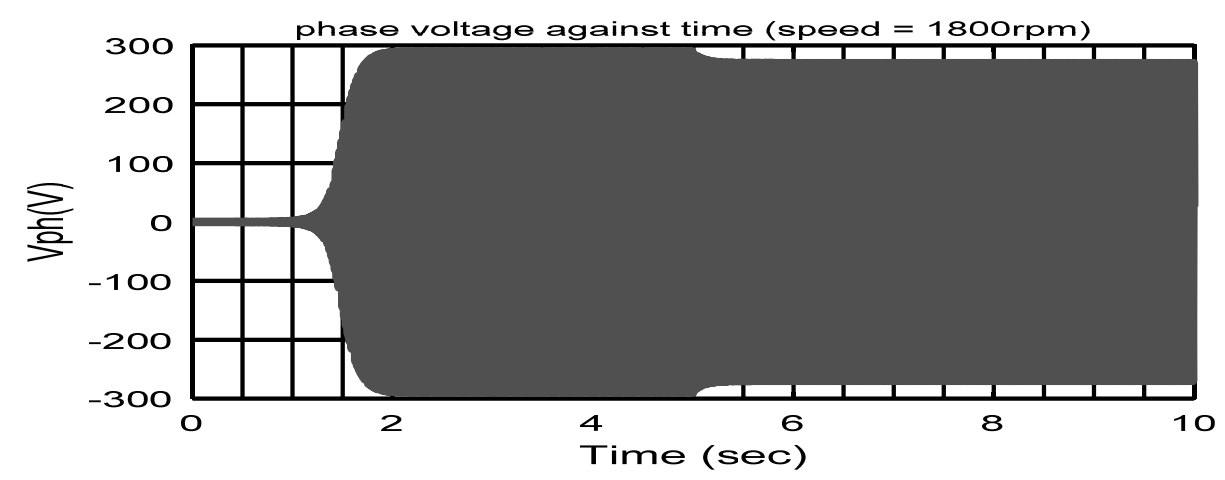

Figure 10. Phase voltage variations on increased speed

\subsection{Loss of Excitation due to Overloading}

The system was overloaded after actualizing excitation at $\mathrm{t}=5 \mathrm{sec}$ and the following simulations show the behavior of the generator.

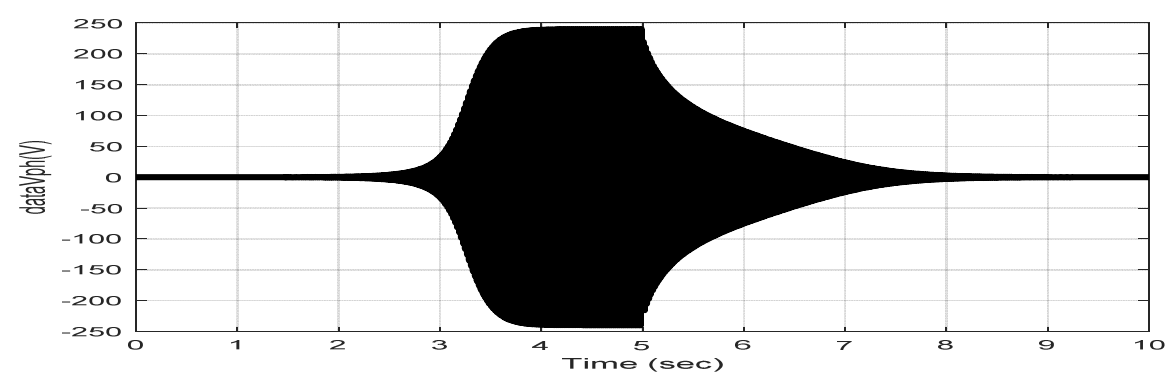

Figure 11. Botched excitation due to heavy load 
Figure 11 shows the effect of overloading leading to excitation loss. Increase in rotor speed or drive torque that is, increasing the capacitor value are different ways by which increased load current could be compensated. Eventually for this case these requirements were not met giving rise to excitation loss.

In a SEIG when load resistance is too small (drawing high load currents), the self-excitation capacitor discharges more quickly, taking the generator to the de-excitation process hence, the rotor speed deviation is proportional to the voltage deviation.

\subsection{Reduced Speed and Loading Effect on Excitation}

Here, the rotor speed was varied to $1485 \mathrm{rpm}$ at $\mathrm{t}=5 \mathrm{~seconds}$. Consequentially, load was applied at $\mathrm{t}=8 \mathrm{~seconds}$ at that same speed of $1485 \mathrm{rpm}$. This resulted to loss of excitation.

The following simulation results were obtained at reduced speed of $\mathrm{t}=5$ seconds and loading at $\mathrm{t}=8$ seconds

i. $\quad \mathrm{C}=130 \mu \mathrm{f}$ at $\mathrm{t}=12 \mathrm{sec}$

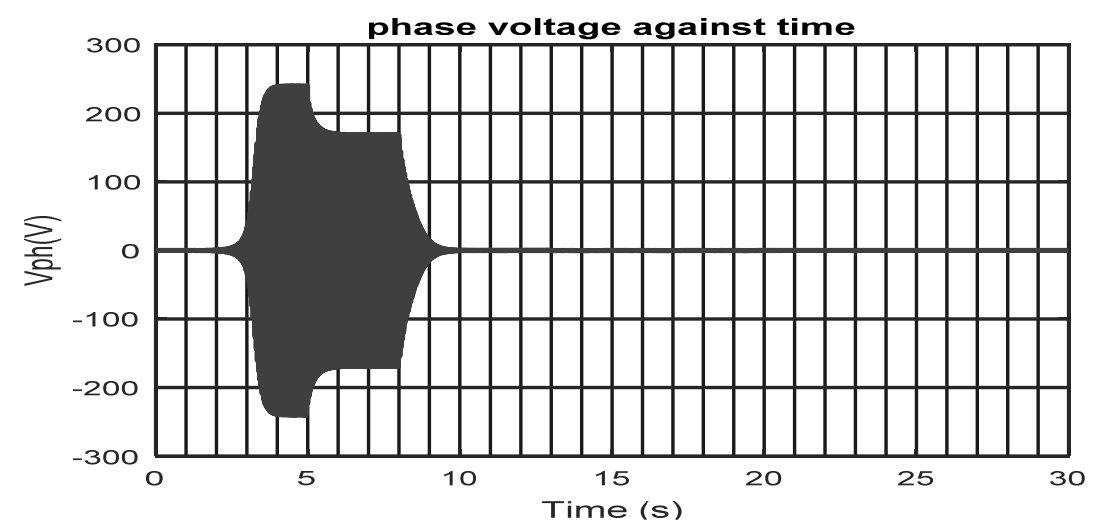

Figure 12. Phase voltage against time at $\mathrm{c}=130 \mu \mathrm{f}$

ii. $\quad \mathrm{C}=140 \mu \mathrm{f}$ at $\mathrm{t}=12 \mathrm{sec}$

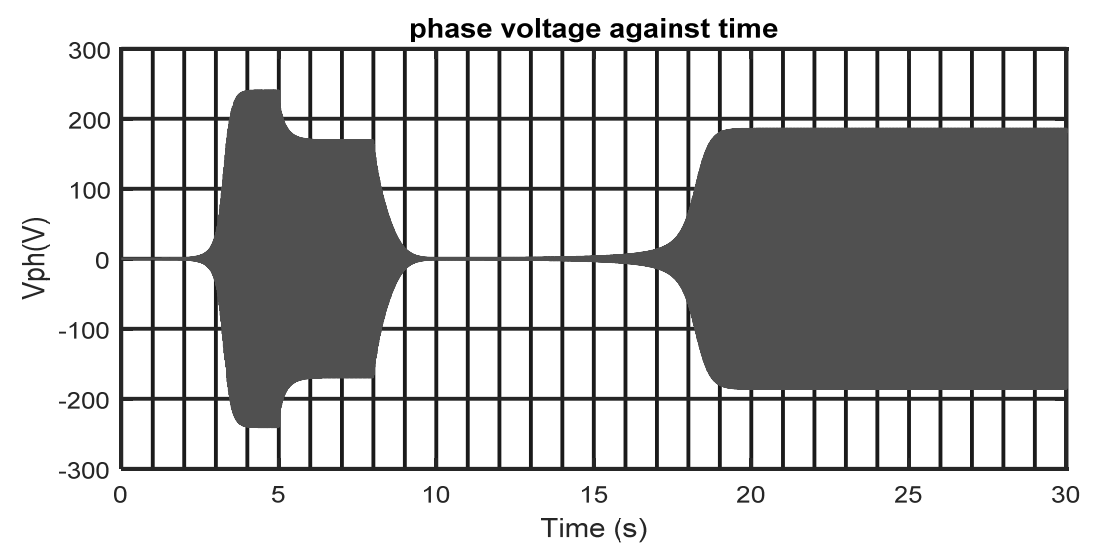

Figure 13. Phase voltage against time at $\mathrm{C}=140 \mu \mathrm{f}$

In figure 12 , the capacitor value was changed to $130 \mu \mathrm{f}$ at $\mathrm{t}=12 \mathrm{sec}$. Due to the capacitor value was not sufficient enough for excitation, there was no voltage value. It shows that for a particular capacitor value, there exist a range for speed and loading to avoid de-excitation.

In figure 13 , the capacitor value was changed to $140 \mu \mathrm{f}$ at $\mathrm{t}=12 \mathrm{sec}$. There was voltage build up for this value of capacitance. The process of excitation requires capacitor banks and is limited to certain speeds and loading of the generator size.

\section{Conclusion}

In this paper, an analysis in respect of wind energy dynamics using electrical generator suitable for wind energy conversion system has been presented. As the wind speed varies for any type of turbine, the rotor speed of the generator varies and it has effect on the voltage generated. A change in the load impedance directly affects the 
machine excitation. The effects of Rotor speed variation and stand-alone generator mode of magnetization inductance on the induction generator were discussed in detail. Going by simulation results as showcased, it can be inferred that the self-excited induction generator (SEIG) is characteristically capable of delivering at adjustable speeds as long as the reactive power is enough. This is because the reactive power of the excitation capacitors is shared by both the induction machine and the load impedance.

Therefore, performance wise, an induction generator can start either loaded or without load, accepts constant and variable loads, and is capable of continuous or intermittent operation and has natural protection against short circuit and over currents through its terminals. That is, if the load current limit is exceeded, de-excitation results because the residual magnetism would have fallen to zero.

\section{Acknowledgments}

Thanks to the Head of Department, Electrical Engineering, University of Nigeria, Nsukka, Enugu State for providing us with the enabling environment for this work. Thanks also to our colleagues who assisted in carrying out of the study.

\section{References}

Tamas, L., \& Szekely, Z. (2013). Modelling and simulation of an induction drive with application to a small wind turbine Generator. Renewable Energy, Croatia, InTech, 227-228.

ni.com (2017). Retrieved June 30, 2017 from http://www.ni.com/white-paper/8189/en/

Masters, G. M. (2004). Wind Power Systems. Renewable and Efficient Electric Power Systems., John Wiley \& Sons, Inc., 310-335.

Hossein-zadeh, N., Wolfs, P., Senini, S., \& Seyoum, D. (2009). A MATLAB/Simulink Model of a Self Excited Induction Generator for an Electrical Brake Application, 2-3.

Umoh, G. D. (2010). Modelling of a Self-Excited Induction Generator. Unpublished M.Eng thesis, Department of Electrical Engineeering, University of Nigeria, Nsukka, 13-32.

Sen, P. C. (January 1996). Principles of electric machines and power electronics, Second ed., United states of America: John Wiley \&Sons, pp. 208, 240.

AI-Nuaim, M. A. (December 2005). Study of the using Induction Generator in wind energy applications. Unpublished thesis report, Electrical Engineering Department, College of Engineering King Saud University, pp 6-16.

Martinez, J. (September 2007). Modelling and Control of Wind Turbines. Unpublished Ph.D thesis, Department of Chemical Engineering and Chemical Technology Imperial College London, London SW7 2AZ, United Kingdom, 20-33.

Luis, J., \& Garcia, D. (April 2009). Modeling and control of Squirrel Cage Induction Generator with Full Power Converter applied to windmills, pp. 25-29.

Basset, E. D., \& Potter, F. M. (May 2009). Capacitive Excitation for Induction Generators. Transactions of the American Institute of Electrical Engineers, 54(5), 540-545.

Ofualagba, G., \& Ubeku, E. U. (June 2011). The Analysis and Modelling of a Self-excited Induction Generator Driven by a Variable Speed Wind Turbine. Fundamental and Advanced Topics in Wind Power, InTech, 5-9.

Obe, E. S., Umoh, G., \& Anih, L. (June 2011). Load Loss Performance of an Autonomous Self-Excited Induction Generator. Nigerian Journal of Technology, 30(2), 2-3.

Ma, D. (May 2012). Self-excited Induction Generator - A Study Based on Nonlinear Dynamic Methods, pp. 1-8.

Etor, M., \& Zou, Y. (May 2013). Simulation Comparisons and Implementation of Induction Generator Wind Power Systems. IEEE, 49(3), 1-2.

Oti, S. E., Nwosu, C. A., \&Agu, M. U. (July 2013). Dynamic Modeling of Self Excited Induction Generator for Enhanced Power Generation, ES4PG 2013, National Conference, University of Nigeria, Nsukka, 21-23 ${ }^{\text {rd }}$, 155-161.

Kumsuwan, P. Y. (September 2013). Design of MATLAB/Simulink Modeling of Fixed-Pitch. Energy Procedia, 34, 363-364.

Singh, G. M. (April 2014). Simulation for Wind Turbine Generators-With FAST and MATLAB-Simulink Modules. NREL/TP, 11-14. 
Swain, A. K. (May 2014). Modelling and Simulation of Stand-Alone Self-Excited Induction Generator for Wind Power Application. Unpublished Thesis M(Tech), Department of Electrical Engineering, National institute of technology, Rourkela, pp. 1-14.

Simoes, M. G., \& Farret, F. A. (August 2015). Modelling and Analysis with Induction generators, third ed., M. H. Rashid, Ed., Boca Raton. CRC press, 38-69.

Wind speed, cut-in and cut-out. (2017). Retrieved July 2017, from http://www.build.com.au/wind-speed-cut-inand-cut-out

Wind Turbine speed (2017). Retrieved July 11, 2017, from http://www.turbinegenerator.org/wind/what-iswind/wind-speed/

Induction generator (2017). Retrieved July 14, 2017, from http://www.alternative-energy-tutorials.com/windenergy/inductiongenerator

\section{Copyrights}

Copyright for this article is retained by the author(s), with first publication rights granted to the journal.

This is an open-access article distributed under the terms and conditions of the Creative Commons Attribution license (http://creativecommons.org/licenses/by/4.0/). 